\title{
APUNTES PARA UNA BIOGRAFIA DE ALEJANDRO KORN
}

\author{
(Años 1860-1883)
}

\begin{abstract}
Su filosofía podría ser cartilla de nuestros jóvenes, norma de nuestros hombres y mandato para nuestros dirigentes. Cuando alcancemos a constituir una colectividad humana regida por esos principios y alentada por esos ideales, habremos alcanzado la categoría de un gran pueblo.
\end{abstract}

ARNAido ORfILA ReyNal.

UACIA 1858 , un joven exiliado alemán llegó al pueblo pampeano de 1 San Vicente, en la Provincia de Buenos Aires, y decidió radicarse en él. El recién llegado se llamaba Carl-Adolf Korn. Había nacido en Breslau en 1820 y era ex oficial del ejército prusiano.

Años atrás, por su participación en las luchas políticas de la Alemania de 1848 , se había visto obligado a abandonar su patria y a refugiarse en Suiza. En Suiza, residió un tiempo en Neuenburg y en la pequeña ciudad de Locle, famosa por sus relojeros. Ejerció en Locle el oficio de pharmatcien, o, más bien de Apothekergebülfe, en la farmacia de un tal Depierre, según informes bilingües de los archivos helvéticos. ${ }^{1}$ Desempeñó este empleo desde 1852 a 1853 . Anteriormente, en Berna, el año 1850 , el ex militar prusiano había declarado ser filólogo. ${ }^{2}$

1 Los informes referidos en el texto fueron enviados al autor de este trabajo por el Director de los Archivos Generales de Suiza, Sr. Leonhard Haas, el cual los despachó en Berna, el 4 de octubre de 1954. Se fundan en documentos en lengua francesa existentes en Neuchãtel, y en lengua alemana, obrantes en los archivos de la Universidad de Zurich y de las ciudades de Zurich y Berna, respectivamente.

2 Según los documentos aludidos en la nota anterior. 
Pero es el caso que ni la milicia, ni la filología ni la farmacopea eran la verdadera vocación del expatriado. El mayor Korn - tal era su rango militar-quería ser médico. $\mathrm{Y}$ por eso ingresó en la Universidad de Zurich, en cuya Mediziniscbe Facultät se matriculó en el verano de 1853 .

No se sabe por qué razón, sin concluir su carrera y tras sólo asistir a clase durante cinco semestres, abandonó sus estudios en Zurich. ${ }^{3}$ Estaba escrito, por otra parte, que no en la patria de Guillermo Tell sino que en la de Martín Fierro, el mayor Carl-Adolf Korn se iba a sentir como en la suya propia. Su destino lo esperaba en la Pampa, en San Vicente, no en Zurich o en Neuchâtel.

San Vicente, al mediar el siglo pasado, no era más que un bastión en plena llanura pampeana. Pero las costumbres patriarcales de los vecinos gauchos, "su idiosincracia y filosófica manera de entender la vida", 4 encariñaron al inmigrante alemán con aquel paisaje. $Y$ allí echó raíces CarlAdolf Korn; alli contrajo matrimonio con María Verena Meyer, muchacha suizo-alemana, natural de Baldingen. $\mathrm{Y}$ allí el mayor Adolf Korn se convirtió en "el doctor Adolfo Korn". Su diploma, nunca obtenido en Suiza, se lo otorgaron ad bonorem los convecinos gauchos de San Vicente y sus aledaños.

Los Korn fundaron un hogar laborioso y feliz. María Verena Meyer era hija de un militar prusiano, el cual, también como el mayor Korn, había emigrado de Alemania a raíz de los sucesos de I848, "después de desobedecer una orden de disparar contra los obreros de una fábrica". " Adolfo Korn y su esposa eran naturalezas afines. No sólo profesaban las mismas ideas en religión y política - ambos eran luteranos, de convicciones liberales-; no sólo hablaban la misma lengua en aquel lugar hasta ayer desconocido, sino que los animaba el mismo espíritu del pioneer afirmativo y voluntarioso que se identifica con la tierra nueva sobre la que edifica su hogar en los límites del desierto.

Una fotografía reproducida más de una vez, muestra el estado actual de la vieja casa de los Korn en San Vicente. ${ }^{6}$ En primer lugar, aparece

3 Según informe del Kanzelei de la Universidad de Zurich, incluido en el referido legajo remitido por el Sr. Haas.

4 Ver el ensayo biográfico del Sr. Luis Aznar en el libro de que es coautor con Francisco Romero y Ângel Vassallo, titulado Alejandro Korn (Buenos Aires: Editorial Losada, S. A., 1940), pág. 95.

5 Según carta personal del Sr. Antonio Ángel Lenuzza, fechada en Buenos Aires el 28 de enero de 1954. El Sr. Lenuzza, para lograr este y otros datos, se entrevistó en la ciudad de La Plata con la hija del filósofo, Da. Inés Korn, y con los señores Francisco Romero y Luis Aznar, en Buenos Aires.

- Ver reproducción de esta fotografía, por ejemplo, en las Obras Completas de A. Korn: (Buenos Aires: Editorial Claridad, 1940), pág. 39. 
la vivienda misma de la familia. Es un edificio de sobria fachada, sin corredor frontero, al que dan acceso varias puertas con cristales. A la derecha se yergue lo que debió de ser la cochera, construcción de tejado de a dos aguas, de estilo criollo. En el patio hay algunos árboles de escaso follaje. Detrás de ambos edificios la vegetación es alta y espesa.

En esta casa nació el primogénito del matrimonio, a quien llamaron Alejandro, el 3 de mayo de 1860 . Según la partida de bautismo No. 729 obrante en el archivo de la Congregación Evangélica Alemana, sita en Buenos Aires, el niño fue bautizado en casa de sus padres, por el pastor Gercke, el día 4 de marzo de 1862 . El nombre completo del flamante cristiano, conforme al citado documento, fue Alexandro Gotthelf Korn. ${ }^{7}$

La primera escuela de Alejandro fue su propio hogar. Sus padres le enseñaron a leer y a escribir. Cuenta un biógrafo que "profesores alemanes le inculcaron luego las nociones correspondientes al ciclo de estudios primarios"s en la casa paterna. Estos profesores debieron de ser los emigrados alemanes de r 848 que frecuentaban el hogar de los Korn; los cuales profesores, según Eugenio Pucciarelli, allí, en el exilio, en plena pampa, aún "mantenían encendida la esperanza en el triunfo" de sus ideas.9

El niño aprendió simultáneamente el alemán y el español, lenguas que llegó a dominar con igual maestría, pues primero fue poeta en alemán y luego escritor filosófico en lúcida prosa española.

Sin duda hubo en aquel hogar de emigrados una atmósfera intelectual que debió de influir profundamente en el espíritu del futuro filósofo. En la casa de San Vicente los refugiados alemanes evocarían los tumultos de Berlín, la actitud equívoca de Federico Guillermo frente a las demandas del pueblo; las barricadas de Frankfort, el entusiasmo revolucionario; comentarian las ideas de Mazzini que eran también las suyas, y se exaltarian con esperanzas y rumores de nuevos alzamientos. Alejandro, oyéndoles hablar de estas cosas, acaso haya tenido así las primeras noticias de la lucha secular por la libertad.

María Verena guardaba como una reliquia la espada de su padre el militar, el cual huyera un día, como se ha dicho antes, hacia tierras libres

7 Copia de esta partida de bautismo fue remitida al autor de estas páginas por Da. Laura del Carmen Santoro de López, acompañada de una carta fechada en San Vicente, el 18 de agosto de 1954. En esta carta asegura la Sra. de Santoro de López que la tradición oral recogida por ella en San Vicente relativa a D. Adolfo Korn, confirma lo que sobre él se dice en el texto.

8 Ver el citado libro de Romero, Vassallo y Aznar (mencionado en nota No. 4), pág. 96.

9 Ver el prólogo de Eugenio Pucciarelli al libro de Alejandro Korn, La Liber. tad creadora (Buenos Aires: Editorial Claridad, 1936), pág. 8. 
para no manchar su acero con sangre de oprimidos. ${ }^{10}$ Evocaciones de jornadas de lucha por la libertad y dignidad humanas, ardorosas esperanzas en la victoria final de las ideas liberales, todo esto sería tema de conversación a la luz de las lámparas de petróleo en la casa de San Vicente. El futuro filósofo de La libertad creadora debió de recibir allí, por vez primera, la vaga inspiración infantil de lo que en su madurez constituiría el corazón de su doctrina filosófica.

Don Adolfo, o como ya lo llamaban los puebleros, el Dr. Adolfo Korn, gozaba de gran predicamento en San Vicente. Ejercía la medicina con algo así como una abnegación apostólica y su idoneidad como galeno era artículo de fe en la comarca. Además, como dedicaba parte de su tiempo a fomentat el cultivo del trigo con nuevos métodos, su fama de sabio entre los agricultores se fundaba en éxitos de evidencia múltiple. Don Adolfo fue quien instaló el primer molino harinero de la zona. ${ }^{11}$ Con los años, su figura, como la del Médicin de Campagne balzaciano, fue asumiendo un prestigio patriarcal.

Un romance salpicado de voces gauchescas, escrito para honrar su memoria, evoca al médico de San Vicente conduciendo su propio coche, con su maletín de instrumentos, camino de la casa de un enfermo:

$$
\begin{aligned}
& \text { Allá va, sereno y solo; } \\
& \text { él es médico y cochero, } \\
& \text { él gusta lo necesario } \\
& \text { desdeñando lo supérfluo; } \\
& \text { él ahorra cuanto puede } \\
& \text { para sus pobres enfermos; } \\
& \text { él pone en la desmayada } \\
& \text { voluntad, soplos de aliento. } \\
& \text { El sabe que hay que curar } \\
& \text { el alma antes del cuerpo. } \\
& \text { Así, de día, de noche, } \\
& \text { en verano y en invierno, } \\
& \text { bajo el sol, bajo la lluvia, }
\end{aligned}
$$

10 Según la citada carta de A. A. Lenuzza. También puede verse el artículo de Alejandro Isusi, "La casa en que escribió y murió Alejandro Korn", La Plata, 2 de diciembre de 1956, en el diario El Día. El St. Isusi hace decir en este artículo a la hija del filósofo, $\mathrm{D}_{2}$. Inés Korn: "Mi abuelo era hijo de un coronel prusiano". Debe de haber aquí un error de imprenta, pues Da. María Verena, abuela de Da. Inés, era hija del nombrado militar.

21 Según Luis Aznar, op. cit., pág. 95. 
en San Vicente le vieron

como un apóstol del bien... ${ }^{12}$

Adolfo Korn era un espíritu altruista lleno de cristiana caridad. Tenía las virtudes que iba a heredar su primogénito. Le gustaba enseñar con la palabra y el ejemplo. Socorría a los humildes, gratuitamente, como médico, y partía su pan con ellos. Era, en suma, un patriarca pampeano, rubio, de grandes bigotes a lo Bismarck, que le llegaban hasta los carrillos, y de unos ojos claros y bondadosos. Su amor a los desvalidos, sus maneras bruscas que disimulaban una fina sensibilidad; su aparente rudeza, su saber y su dinamismo emprendedor, todo esto contribuyó a que los gauchos vieran en él un hombre extraordinario, fuerte y duro para el trabajo como ellos, aunque muy superior por la cultura y el carácter. Por eso dice el autor del "Romance del doctor Korn" que

en vida le tributaron
homenajes muy sinceros:
dieron su nombre a una plaza
y a una calle de aquel pueblo... ${ }^{13}$

Este prócer pampeano arropado en su negro levitón, sudoroso el rostro bajo la alta chistera, que saludaba campechanamente a los gauchos que pasaban a su vera mientras iba él a visitar a sus enfermos con el inseparable maletín, hubiera podido ser un admirable personaje gringo de una novela de Benito Lynch. Dos días antes de morir, estando ya muy enfermo, durante una noche de tormenta, acudió al rancho de uno de sus protegidos y salvó una vida. Falleció en 1902 . Sus restos están sepultados en el cementerio protestante de San Vicente. Todavía hoy la calle de la quinta del médico agricultor lleva el nombre de Adolfo Korn.

Casi nada se sabe de la madre del entonces futuro filósofo. ¿La conoció don Adolfo Korn en Suiza o en San Vicente? ¿Emigró María Meyer a la Argentina antes que su esposo? Consta en los archivos de Zurich que Adolfo Korn vivió en 1853 y en 1854 en casa de una familia Meyer de esa ciudad. Pero ignoramos que estos Meyer hayan sido o no deudos de María Verena. ${ }^{14}$

12 Ver el folleto de Armando C. Báez Langet, Romance del doctor Korn (La Plata: Renovación, 1947), págs. 9-10.

13 Ibid.

14 Según informe del Archivo de la ciudad de Zurich, firmado por Paul Guyer, el 21 de septiembre de 1954. 
No es difícil, sin embargo, imaginarla como a una mujer hacendosa, consagrada a las labores domésticas, yendo de una habitación a otra, lustrando muebles y objetos, ordenando la ropa blanca en las cómodas y vigilando el trabajo de las criadas. ¿Cómo sería el interior de la morada que fue el centro de su vida?

Sarmiento, en su Facundo, describe los hogares alemanes de la pampa al sur de Buenos Aires, esto es, los situados en la zona de San Vicente y sus alrededores:

"El amueblado [es] sencillo pero completo; la vajilla, de cobre o de estaño, reluciendo siempre; la cama, con cortinillas graciosas y los habitantes en un movimiento y acción continuos". ${ }^{1 \sigma}$ Así sería por dentro la vivienda de esta señora educada en Zurich, ${ }^{16}$ que venía de una civilización muy avanzada a una comarca casi bárbara. Y la imaginamos empeñada en dar a su hogar pampeano, en que guardaba algunos recuerdos de su familia y de su tierra - la referida espada, algún reloj primoroso, viejos retratos y algunos utensilios antiguos-la limpieza y el orden de su casa natal de Suiza.

\section{II}

La infancia de Alejandro Korn transcurrió en aquel pueblo de gauchos. La población de San Vicente era casi en su totalidad criolla: chinos y chinas ignorantes, rudos, ingenuos y ladinos a un tiempo, que veían en la germánica familia Korn algo exótico y digno de curiosidad y admiración. El niño Alejandro los admiraba por su rubicundez. Lo llamaban el alemancito y, cuando había reunión social en el pago, se "lo pedían prestado" a sus padres para exhibirlo a los forasteros:

- ¿Me prestan el rubio para el rancho, que hoy hay visitas ${ }^{17}$

Alejandro era voluntarioso, obstinado y algo arisco. No en vano había nacido en la Pampa, de una pareja de pioneers y no en vano llevaba en las venas sangre de militares rebeldes. A menudo Alejandro desaparecía de su casa durante horas y se refugiaba entre los cardos. Esto hacía siempre que se enfadaba. Era menester entonces ir a buscarlo, lejos, en el campo, y halagarlo para que regresara al hogar. El niño, en contacto continuo con los gauchos, se hizo a la vida y costumbres pampeanas, aprendió el gracioso dialecto de la comarca, llegó a ser consumado jinete feliz de galo-

15 D. F. Sarmiento, Facundo (Madrid: Editorial América, s. f.,), pág. 29.

16 Según la referida carta del Sr. Lenuzza.

17 Ver también el citado artículo del Sr. Isusi. 
par por la llanura; fue, en suma, un gauchito más instruido que los otros pues tenía profesores que le hacían leer en alemán a Goethe y a Heine, pero igual a los demás muchachos en las destrezas de la vida pampera.

Lector desde niño de grandes autores alemanes, y en especial de los poetas citados, quiso más tarde cantar a su pampa nativa en la lengua exótica que a él le era familiar como la jerga del gaucho. Y lo hizo en sonoros versos alemanes que ha traducido Ennesto Palacio:

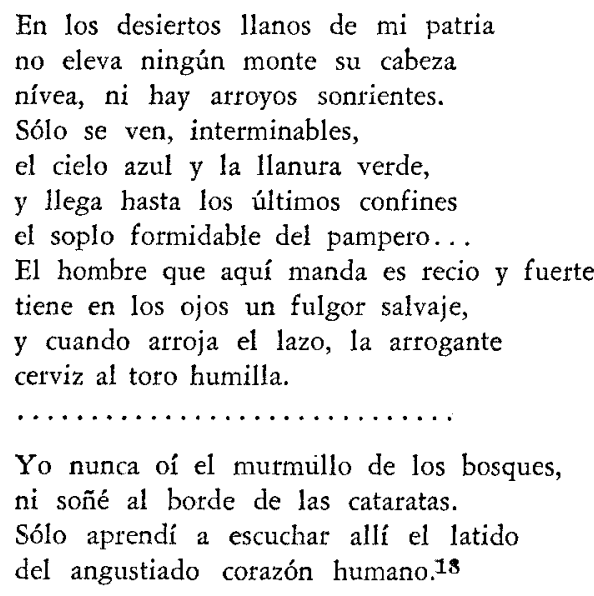

En la pampa, que fue su único paisaje, Korn, rodeado de gauchos, leyó en las almas de éstos la íntima angustia universal del hombre. $Y$ pudo en los gauchos comprender al Hombre porque él también fue un gaucho. Un gaucho que abandonó la llanura nativa para escalar más tarde, no las cumbres de montañas allá inexistentes, sino las del pensamiento. Desde esas alturas este gaucho rubio iba a poder señalar una ruta nueva para el desarrollo moral e intelectual de su patria. Pero no nos anticipemos.

\section{III}

Cuando el muchacho cumplió los doce años se decidió que debía ir a Buenos Aires a fin de cursar los años del bachillerato. Nada se sabe de la vida del niño gaucho en Buenos Aires. Y nada o casi nada de sus estudios en el colegio a que asistió.

18 Alejandro Korn, Poemas (Buenos Aires: Universidad de Buenos Aires, Inștitụto de Esstudịoș Gẹtmániços, 1942), págs. 55-59, 
La capital argentina era cuando Korn la vió por primera vez la Gran Aldea que ha descrito Lucio V. López. El censo hecho en 1869 , esto es, tres años antes de la llegada de Korn a Buenos Aires, revela que la ciudad tenía entonces I 87,000 habitantes. En vida de Korn esa cifra se multiplicaría varias veces.

Las calles de la Gran Aldea estaban mal empedradas; había aceras altísimas, de las que se bajaba a la calzada, en las esquinas, por escalones muy gastados. Las damas, al descender por ellos, debían apoyarse en algún cañón de bronce que manos municipales habían colocado allí para el efecto. Las casas, de arquitectura colonial, de fresco y amplio zaguán, tenían patios entoldados, con un aljibe en el centro, no lejos del cual reposaban los porteños, cuando hacia calor, sesteando en perezosas hamacas. A la sombra de los toldos, cerca de la frescura vegetal de algún banano, se tomaba mate, cebado por criaditas negras.

En las calles voceaban vendedores ambulantes y rodaban carros, coches y tranvías tirados por corpulentos caballos. Los hombres circulaban lentamente por las aceras, vestidos en su mayoría de negro, con sombrero de copa. Las mujeres, con largos vestidos de talle alto pasaban protegidas del sol por sus sombrillas. En las bocacalles dirigían el tránsito policías de largos bigotes con su uniforme de paño oscuro y brillantes botones de metal, la espada al cinto y en la cabeza el kepí.

En la Plaza de la Victoria se erguía la Pirámide no lejos de la fuente y de la estatua de Belgrano. En torno a la plaza se estacionaban coches de uno o dos caballos. El Cabildo estaba casi tal cual lo vieran los patriotas en aquel lluvioso 25 de Mayo de rgro: lo rodeaban edificios bajos, hoy demolidos hace mucho tiempo. La catedral, con sus doce columnas de estilo corintio, hacía extraño contraste con los viejos edificios coloniales.

En la orilla del río, innumerables lavanderas pasaban mañana y tarde en rítmica faena. Mucha ropa tendida al sol ondeaba al viento a lo largo de la playa. La primera impresión de los que de Europa llegaban a Buenos Aires, no era grata. Pero al niño de la pampa, la Gran Aldea debió de parecerle imponente.

\section{IV}

¿Cómo era la vida en el Colegio Nacional a que asistió Alejandro Korn? Nos complacemos en imaginarla muy semejante a la vida estudiantil

19 Aníbal Latino, Buevos Aires por dentro (Buenos Aires: Imprenta y Libtę. ría de Mayo, 1886), pág. 13. 
que Miguel Cané describe en su Juvenilla. Pero esto sólo debemos imaginarlo, ya que nada sabemos en concreto.

Son conocidas, sí, las clasificaciones que obtuvo Korn en el colegio desde 1873 hasta su egreso en I876. Ellas revelan que fue buen alumno - pero nada más que buen alumno- en francés, en latín, en historia natural, en matemáticas, en química inorgánica y en química analítica. En estas asignaturas los examinadores lo declararon "Bueno por unanimidad" o "Bueno por mayoría". Pero en literatura y en química orgánica, respectivamente, lo declararon "Distinguido por unanimidad" y "Muy distinguido".

En filosofía y en historia, disciplinas en que años más tarde sería $\tan$ versado y a las que se consagraría con apasionado ardor durante casi medio siglo, el muchacho no parece haber revelado un interés precoz. En ambas materias Alejandro resultó "aprobado con siete puntos". En física, lo aprobaron con ocho.

Hay que subrayar, sin embargo, el hecho de que Korn se presentaba a dar exámenes de dos o más cursos de una misma materia en una misma fecha, y que esto bien puede explicar el que sus clasificaciones no hayan sido más altas. ${ }^{20}$

Después de terminar el bachillerato, Korn ingresó en la Universidad de Buenos Aires para estudiar medicina. Durante los dos primeros años, es decir, en los cursos correspondientes a 1877 y 1878 , Korn fue un alumno "Distinguido con 17 puntos". Pero, durante el tercero y el cuarto curso, el futuro médico-filósofo no salió tan bien. O sea, los aprobó con la clasificación de "regular", con ocho y once puntos, respectivamente. Durante el quinto y el sexto año, lo declararon "Bueno". Nada más que "Bueno", sin especificación de puntos.

En marzo de 1883 se presentó el estudiante al llamado "Examen general de Medicina", dividido en aquel entonces en tres términos. En los dos primeros términos obtuvo la nota de "Bueno, cociente cinco". En el tercero salió con la de "Distinguido, cociente ocho". ${ }^{21}$

Por fin, el examen de tesis lo aprobó Korn el Ir de junio de I883. Este fue el año en que se doctoró, y no el I882, como creen algunos biógrafos. ${ }^{22}$

20 Según informe del Decano de la Facultad de Ciencias Médicas de la Universidad de Buenos Aires, Dr. Felipe M. Cía, fechado en Buenos Aires, el 15 de noviembre de 1954.

21 Ibid.

22 Tanto Francisco Romero como Luis Aznar y Arnaldo Orfilia Reynal, dicen que Korn se doctoró a los "22 años". Pero como Korn nació en mayo de 1860 


\section{V}

Antes de hablar del médico recién diplomado, convendrá relatar lo poco que se sabe de la vida de Korn como estudiante de medicina.

En I880, esto es, cuando el estudiante cursaba el cuarto año de su carrera, le tocó actuar en el combate de Los Corrales, sangriento episodio de la revolución de aquel año.

Dos palabras acerca de esta revolución.

En junio de i880 el gobernador de la Provincia de Buenos Aires, Dr. Carlos Tejedor, se alzó en armas contra el gobierno federal presidido por Nicolás Avellaneda. Aconteció esto porque todavía en aquel tiempo coexistían en la ciudad de Buenos Aires el gobierno nacional y el gobierno provincial, lo cual creaba situaciones tensas y cruentas rivalidades. La rivalidad era en I880 entre el ex ministro de guerra de Avellaneda, general Julio A. Roca, y el gobernador de la Provincia, Dr. Tejedor.

Tejedor, distinguido jurista, y Roca, gran militar, pacificador de la Patagonia, aspiraban a la presidencia de la nación. En vísperas de las elecciones, Tejedor movilizó fuerzas provinciales. El gobierno federal se opuso a esta medida. Y por esta razón comenzó la lucha entre las fuerzas de los dos gobiernos.

Los tres combates más encarnizados se libraron en Barracas, Puente Alsina y Los Corrales. Korn actuó en este último combate, como miembro del servicio sanitario. Allí, según cuenta Eugenio Pucciarelli,

pudo apreciar desde cerca la barbarie de nuestras luchas civiles: en una escena inolvidable, en Los Corrales, después de un encuentro, quedan tendidos en el campo muchos hombres. Uno de ellos sufre y se desangra inútilmente.

Su compañero - un mestizo de escasa talla, semilampiño, de cara tostada - se acerca al estudiante de medicina y le propone 'despenar' al moribundo. El sol de la llanura sin árboles y la sed, más intolerable que el hambre, se unian para exacerbar el tormento de los heridos y prolongar vanamente su agonía. Abreviarla era una práctica humanitaria sugerida por la Naturaleza misma...23

Pucciarelli relata este episodio de pasada, sólo para darnos una idea

y se doctoró en junio de 1883 , resulta que en esta última fecha tenía 23 y no 22 años. Véase el notable prólogo de Francisco Romero a las citadas Obras completas de Korn, referidas en nota No. 6; el ensayo de Luis Aznar referido en nota No. 4 y el folleto de Arnaldo Orfila Reynal, Alejandro Korn. Argentino ejemplar (Bahia Blanca: Colegio Libre de Estudios Superiores, 1943), pág. 6.

23 Ver el prólogo aludido en notạ No, 9. 
de cuán rica fue la vida de Korn en experiencias múltiples y para indicar que no en las aulas ni en los libros, sino que en plena pampa recibió aquel estudiante su primera lección de eutanasia artificial. Y apunta que, en Los Corrales, Korn rechazó indignado la proposición del mestizo y que sólo años más tarde cayó en la cuenta de su "error inicial".

Los demás episodios conocidos de la vida estudiantil de Korn los ha contado él mismo en la "Epístola a Cocobacilo", recogida entre sus obras completas. Alejandro Korn escribió esta epístola en I924, aparentemente al director de un periódico. Ahora bien: según Luis Aznar, la epístola no es nada más que una fantasía humorística de dudoso contenido histórico. ${ }^{24}$

Sin embargo, y aun en el caso de que sólo fuera un divertido jeu d'esprit, la epístola no dejaría de ser un documento. Un valioso documento revelador del humorismo de Alejandro Korn.

Aquí haremos un intento de determinar lo que en la epístola sea verosímil y lo que haya en ella de pura broma.

Las reminiscencias insertas en ella, verdaderas o imaginadas, abarcan un período de varios años. La primera parte de la epístola se refiere a época propiamente estudiantil de Korn, a sus recuerdos de la Facultad de Medicina; la segunda, a su actuación como practicante en la Administración de Vacuna y en la Penitenciaría Nacional. La tercera evoca su nombramiento y servicios como director del Hospital Provincial de Alienados, y su comentario será dejado para después.

Jocosas, zumbonas, las dos primeras partes constituyen una alegre sátira de la Facultad de Medicina y de la Administración de Vacuna allá por el año r880. También hacen burla del saber científico del propio Korn en los primeros años de su carrera médica.

¿Cómo era el "matadero", es decir, el anfiteatro bajo cuyo techo se reunían Korn y sus condiscípulos para estudiar anatomía, en torno a la mesa de mármol presidida por el profesor González Catán?

Los días de lluvia-escribe Korn-el techo del soi disant anfiteatro se convertía en una criba y sin duda allí nació la higiénica invención de los baños de regadera, destinados a reemplazar a los de tinaja, únicos conocidos, y eso en las mejores casas de la capital. Por suette, entre los alumnos los había muy distinguidos. Nunca faltaba alguno que todavía no había empeñado el paraguas y ahora lo desplegaba orondo y protector, sobre la calva del maestro. Así aprendimos anatomía por un método algo distinto del que

24 Según declaración del Sr. Aznar al Sr. A. A. Lenuzza, inserta en la citada carta de este último. 
pretende implantar el espíritu innovador y un tanto demagogo del Di. Avelino Gutiérrez. Es de sentir, no haya usted concurrido a aquellas clases, pues 'La lección de Anatomía' que habría escrito, hubiera sido muy superior a la que pintó un tal Rembrandt...25

Este maestro cuya calva cabeza protegía el paraguas de un discípulo oficioso, ¿es un personaje histórico? Sin duda alguna: su nombre completo era Mauricio González Catán; había nacido en Buenos Aires el 23 de septiembre de 1823 y obtenido su título de doctor en I845. Durante la tiranía de Rosas el Dr. González Catán fue encarcelado. En la batalla de Caseros actuó como médico jefe del ejército de Urquiza... En I874 lo nombraron profesor de Anatomía de la Universidad de Buenos Aires; llegó a ser decano de la Facultad respectiva en I889..26

El hecho de que el primer profesor que menciona Korn en la epístola sea un personaje histótico, nos hace creer en la veracidad fundamental de ese documento humorístico. Es, pues, de suponer que al escribir la epístola, Korn evocara hechos verdaderos a los que la burla les da una apariencia inverosimil.

¿A qué se debe entonces el tono burlón? Sencillamente a que en el espíritu de Korn tanto el anfiteatro como el profesor de anatomía que en él enseñaba no merecían una evocación reverente.

Veamos ahora el argumento irónico que esgrime el mismo Korn para asegurar por qué el transcurso del tiempo no ha podido desfigurar los hechos ni confundir sus recuerdos:

Usted ha evocado en mí el recuerdo de gentes y de cosas ya lejanas. Pero precisamente estas reminiscencias remotas, mi memoria las retiene vivas, cosa que no suele ocurrir con impresiones más recientes. La bondad de usted le ha de impedir attibuir este extraño fenómeno psicológico a algún achaque del tiempo. En realidad, la explicación es otra. La ciencia que nos transmitieron, no molestaba por su volumen y ba sido fácil conservarla, con la imagen de sus dignos maestros...27

La ingratitud es inconcebible en un hombre como Korn, cuya vida es un ejemplo de generosidad, de magnanimidad. En caso de haber recibido de sus maestros una sólida información científica, no hubiera él afirmado nunca, ni aun en broma, que la enseñanza de aquéllos resultó inolvidable por lo escasa. Y adviértase que Korn no habla de lo que él aprendió de sus maestros sino de lo que ellos le trasmitieron.

25 Obras completas, págs. 725-728.

26 Véase el Diccionario Biográfico Argentino, de Guillęrmo Udoando.

27 lbid. 
La burla, pues, se dirige a ellos, no a sí mismo ni a su falta de aplicación como estudiante, cosa esta última muy fácil de comprender como mero chiste o como efectiva confesión.

En seguida Korn evoca a otro profesor, "alma ingenua y afable", "el cual enseñaba no sé qué materia, por no sé qué texto, pero página por página nos hacía repetir". ${ }^{28}$ Otro de los profesores satirizados aparece en la epístola con el nombre de "don Cleto", a secas. Don Cleto, según Korn, "era la misma mansedumbre en dos pies, salvo en casa y fuera de ella. Un ariete civilizado..."

El director de la Administración de Vacuna se llamaba Justo Meza, el Dr. Justo Meza. Korn lo recuerda como al "más celoso de los funcionarios públicos". El estudiante comenzó a trabajar en la oficina de este funcionario con un sueldo de veinte pesos mensuales. "No [se] suponga que he sido portero" - aclara Korn-: "fui practicante vacunador".

Algunos párrafos de la epístola recuerdan episodios de novela picaresca. Léase, por ejemplo, el elogio del jefe de la Administración de Vacuna:

Inolvidable doctor Meza. Su cabello, con brillo metálico, reflejaba todos los matices del arco iris y su alma irisaba en todos los fulgores del sentimiento poético. Cuando me trasmitía una orden escrita, solía terminar: 'Lo saluda con firmeza, su amigo Justo Meza'. Había olvidado la prosa. Todos los años elevaba a la superioridad una extensa memoria, toda ella versificada. Quizá allí esté el verdadero origen de los premios municipales. Por mi parte, ante este ejemplo, aunque en edad temprana, renuncié para siempre a escribir versos. 30

(Esto último no es cierto, pues Korn siguió escribiendo versos, ocasionalmente, hasta el final de su vida).

En los párrafos siguientes de la epístola, el tono de novela picaresca se acentúa. Y advertimos que no es sólo el carácter autobiográfico e irónico de la narración lo que nos recuerda la ficción picaresca, sino también las bruscas transiciones del relato producidas al cambiar el protagonista un empleo por otro:

A poco andar vine a parar tres años en la Penitenciaría; se sobreentiende que también como practicante. Allí me hice de relaciones si no muy selectas, por lo menos interesantes $y$ pronto me di cuenta de los secretos del oficio.

28 Ibid.

29 Ibid.

30 lbid. 
Apenas entraba en el consultorio un presunto enfermo, ya había la dosis de bicarbonato de sodio que había de propinarle, en una porción de jarabe de genciana para no dulcificar la existencia de estos criminales mañeros. No podia, empero, prescindir del interrogatorio ritual, y al fin incurría en una pregunta impertinente.

En el siguiente diálogo hay que poner por una parte la petulancia juvenil del caso, y por otra la sorna criolla del compadre.

- ¿Y por qué estás preso?

-Por sospechas.

- ¿Sospechas de qué?

-De tentativa.

-Pero demonio, ¿tentativa de qué?

-De ebriedad...31

Aquí no cabe duda de que ese diálogo tiene una autenticidad de suceso vivido. Esta es una de esas anécdotas que no se inventan, aunque se transformen un tanto al contarlas una y otra vez. Consta, por otro lado, que Korn fue practicante de la Penitenciaría Nacional. Un informe firmado por el director de este establecimiento penal en agosto de I954, dice:

El ex-agente de referencia [Alejandro Korn] fue dado de alta en esta Unidad el día 17 de marzo de 1881 en el cargo de Practicante, revistando hasta el día 8 de junio de 1883, fecha en que le fuera aceptada la renuncia al cargo. Desde la fecha de su ingreso hasta el mes de diciembre de 1882, percibió una remuneración de mensual de $\$ 48,00$ y a partir del mes de enero de 1883 hasta la fecha de la renuncia, la suma de $\$ 51,66$ por el mismo concepto. 32

VI

La "Epístola a Cocobacilo" relata después el examen final del estudiante Korn:

Fue un examen sensacional: hice una admirable aplicación de forceps sobre un feto de trapo y con pelvis de cartón. Desgraciadamente se me ocurrió balbucear algo sobre antisepsia. Alli fue Troya.

¿Cómo' - me dijo con solemne serenidad uno de los miembros de la mesa"usted se atrevería a interrumpir el proceso que la Naturaleza ha establecido con sabia previsión y que debe merecerle el más religioso respeto ?33

31 Ibid.

32 Según nota No. 241 del director Lorenzo T. M. Zunino, fechada en agosto de 1954.

33 Korn, op. cit., p. 727. 
Agrega Korn que el examinador que así le había interrogado se negaba a hacer uso del microscopio de miedo a ver, efectivamente, microbios. Prefería no querer convencerse de la existencia de estos organismos diminutos porque si tal cosa ocurría, iba a tener que "rectificar toda su Weltanschaung, y ya no estaba el horno para bollos". ${ }^{34}$

El examen de tesis, sin embargo, no fue tan sensaional como el relatado más arriba. Y eso que la única dificultad que el examinando esperaba tener que superar era la de conseguir el frac de rigor para la ocasión. Esta dificultad, felizmente, no fue tan grave, pues como el mismo Korn advierte, bastaba la mera posesión y no era menester "probar su adquisición legítima". ${ }^{35}$

No explica Korn por qué su tesis - Locura y crimen-corrió el riesgo de ser rechazada. Parece que le arguyeron que ella atentaba "contra los más sagrados principios del orden social", y que sólo la intervención de su "bondadoso padrino, el doctor Blancas", fue aceptada por el tribunal examinador. El repudio de la tesis hubiera sido injusto, comenta su autor, porque él ya había escrito otras dos que fueran aprobadas sin tropiezo...

Esto significa que sus condiscípulos reconocían ya en él dotes de escritor. El mismo Korn nos cuenta que cuando sus camaradas le pedían ayuda literaria, unían a la petición este equívoco elogio de sus dotes:

-Che, Inglés, prestá una manito, vos que sabés macanear.

$\mathrm{La}$ autenticidad de esta reminiscencia parece indubitable.

\section{VII}

Según el biógrafo Luis Aznar, Alejandro Korn empezó a ejercer la medicina en el pueblo de Ranchos. La "Epístola a Cocobacilo", en vez de Ranchos, dice Chinchigasta. (Al parecer, Korn, a una modificación de la palabra "chinche" ha añadido el sufijo "gasta"):

"Pintoresco pueblo" — dice- "donde el destino me llevó a ejercer la medicina rural, con una competencia enciclopédica... Puedo asegurarle que, si bien distraído con frecuencia por preocupaciones de otra indole, alcancé realmente a observar algunos enfermos, a puro ojo clínico. Temeroso de hacer daño, persistí siempre en el empleo de mi panacea, el bicarbonato de sodio, pero ya entonces con jarabe de violetas silvestres..." 36

34 Ibid.

35 Ibid.

36 Ibid. 
Esto parece arrancado de las memorias de Gil Blas de Santillana, de los capítulos en que el héroe de Lesage se hace médico bajo la égida del doctor Sagredo. Demás está decir que el uso exclusivo de tal "panacea" es sólo una broma del Dr. Korn, el cual, cuando escribió la epístola aquí comentada, ya era profesor de prestigio en dos Universidades y, además, autor de una obra clásica de historia de las ideas filosóficas en la Argentina.

Esto es todo o casi todo lo que se sabe de la vida de Alejandro Korn hasta la fecha de su iniciación como médico rural. Lo demás será relatado en otra ocasión.

Hugo Rodríguez Alcalá, Universidad de Wasbingion. 